\title{
Perubahan Penguasaan Konsep Mekanika Newtonan Melalui Pembelajaran Collaborative Inquiry (CI) Berbasis Diagram Interaksi
}

\author{
${ }^{1}$ Abu Zainuddin, ${ }^{2}$ Sentot Kusairi, ${ }^{3}$ Siti Zulaikah \\ ${ }^{1}$ Pendidikan Fisika, FMIPA, Universitas Negeri Surabaya \\ ${ }^{2,3}$ Pendidikan Fisika, FMIPA, Universitas Negeri Malang
}

Email: 1abuzainuddin@unesa.ac.id, 2sentot.kusairi.fmipa@um.ac.id, 3siti.zulaikah.fmipa@um.ac.id

Tersedia Online di

http://www.jurnal.unublitar.ac.id/ index.php/briliant

\section{Sejarah Artikel}

Diterima pada 15 Februari 2020

Disetuji pada 24 Februari 2020

Dipublikasikan pada 29 Februari

2020 Hal. 151- 162

\begin{tabular}{l}
\hline Kata Kunci: \\
\hline $\begin{array}{l}\text { Penguasaan konsep; collaborative } \\
\text { inquiry; diagram interaksi }\end{array}$ \\
\hline DOI: \\
\hline http://dx.doi.org/10.28926/briliant \\
.v3i4.443
\end{tabular}

\begin{abstract}
Abstrak: Penelitian bertujuan mengungkap perubahan penguasaan konsep Mekanika Newtonan mahasiswa yang menempuh Mata kuliah Fisika Sekolah di Universitas Negeri Surabaya setelah pembelajaran Collaborative Inquiry berbasis diagram diagram interaksi. Peningkatan penguasaan konsep diukur dengan 20 butir soal pilihan ganda beralasan. Berdasarkan hasil uji tberpasangan diperoleh $\mathrm{t}=-11.6$ dengan sig. $=0.00$ yang menunjukkan bahwa skor pretest dan postest berbeda secara signifikan. Peningkatan tersebut dalam kategori sedang, diindikasikan dengan $\mathrm{N}$ gain 0.38. Perbedaan skor dengan kategori kuat diindikasikan oleh effect size 2,17. Selain itu, peningkatan penguasaan konsep diindikasi dari bertambahnya jumlah mahasiswa yang memberikan alasan benar dalam menjawab soal terutama dalam memahami konsep gaya.
\end{abstract}

\section{PENDAHULUAN}

Salah satu tujuan pembelajaran fisika adalah agar mahasiswa mampu menguasai konsep secara mendalam hingga mampu menggunakannya dalam memecahkan masalah, sehingga dalam beberapa dekade ini banyak peneliti mencurahkan perhatiannya pada upaya tersebut. Penelitian pada ranah tersebut secara umum difokuskan pada tiga topik besar, yakni mengidentifikasi prekonsepsi yang terjadi pada peserta didik, mengembangkan dan mengevaluasi pembelajaran untuk mengatasi miskonsepsi, dan menjelaskan struktur pengetahuan dalam memori peserta didik (Docktor \& Mestre, 2014; Sutopo, 2016). Dari ketiga topik besar penelitian tersebut, penelitian yang paling sering dilakukan adalah mengenai miskonsepsi maupun penguasaan konsep mahasiswa secara umum (Saputri et al., 2019; Taqwa \& Pilendia, 2018; Taqwa et al., 2019; Taqwa \& Rivaldo, 2019). Selain itu, banyak peneliti yang memfokuskan perhatiannya dalam mengidentifikasi konsepsi mahasiswa pada topik-topik dalam lingkupan mekanika Newtonan.

Besarnya perhatian para peneliti pada pokok bahasan mekanika Newtonan didasari pada pemikiran bahwa pokok bahasan tersebut sangat esensial dan merupakan dasar pengetahuan dalam memahami konsep-konsep fisika 
lainnya. Hestenes \& Wells (1992) memberikan klaim bahwa mahasiswa yang menguasai konsep mekanika Newtonan dengan baik, maka ia akan mampu mempelajari cabang ilmu fisika lain dengan mudah. Sebaliknya, mahasiswa dengan penguasaan konsep yang rendah ataupun mengalami miskonsepsi maka akan sulit memahami konsep-konsep fisika lainnya.

Meskipun penelitian mekanika Newtonan sudah banyak dilakukan, namun hingga saat ini masih tetap banyak kesulitan-kesulitan mahasiswa dalam memahami konsep bahkan setelah mengikuti perkuliahan (Sutopo, 2012). Kesulitan tersebut disebabkan oleh gagalnya mahasiswa dalam memahami konsep-konsep esensial dalam mekanika seperti konsep vektor (Flores et al., 2004; Knight, 1995; Nguyen \& Meltzer, 2003; Shaffer \& McDermott, 2005), jarak tempuh dan posisi (Taqwa \& Rivaldo, 2018), kecepatan dan percepatan (Angin et al., 2017; Taqwa et al., 2017), dan gaya (Clement, 1982; Gilbert \& Watts, 1983; Halloun \& Hestenes, 1985; Taqwa, 2017; Taqwa \& Pilendia, 2018).

Kesulitan-kesulitan tersebut sering kali disebabkan karena mahasiswa telah memiliki pengetahuan sebelum perkuliahan (prakonsepsi). Terkadang pengetahuan yang dimiliki tidak sesuai dengan konsep ilmiah yang disepakati (Başer, 2006). Dengan adanya permasalahan tersebut perlu langkah penting untuk memperbaiki struktur kognisi yang dimiliki oleh mahasiswa dengan pengetahuan baru yang benar serta memperkuat dan memperdalam pemahaman mahasiswa terhadap konsep-konsep fisis. Namun prekonsepsi yang dimiliki oleh mahasiswa tersebut cenderung retensi dan sulit untuk diubah (Berek et al., 2016). Pembelajaran dengan misi memperbaiki struktur pengetahuan dan memperdalam pemahaman konsep mahasiswa tidak cukup dengan pembelajaran yang sematamata memberikan informasi secara lisan.

Agar pembelajaran yang dilaksanakan mampu memperbaiki struktur kognisi mahasiswa maka pembelajaran yang dilaksanakan harus mampu memfasilitasi mahasiswa untuk mengembangkan konsep-konsep baru dan memperbaiki cara berpikir sebelumnya agar sesuai dengan konsep ilmiah (Arends, 2008; Atasoy et al., 2011; Aufschnaiter \& Rogge, 2010). Dua hal penting untuk mencapai misi tersebut yakni, (1) pembelajaran dilakukan untuk melatih mahasiswa dalam memahami dan mengaplikasikan konsep sains dan metodenya, bukan hanya sekedar mengingat konsep-konsep fisis (Bell, 2010), dan (2) pembelajaran harus melibatkan mahasiswa secara aktif mengingat pentingnya membangun pengetahuan dengan berkolaborasi. Mengingat pentingnya dua hal tersebut, maka pembelajaran dengan menggunakan model Collaborative Inquiry (CI) dapat dijadikan salah satu alternatif pembelajaran untuk mencapai misi perubahan stuktur kognisi mahasiswa. Pembelajaran CI yang dimaksud adalah yang dikembangkan oleh Donohoo (2011).

Pembelajaran inquiry pada dasarnya lebih mementingkan pada pemahaman konsep dan penerapan konsep dan metode ilmiah, bukan sekedar memorisasi fakta dan informasi ilmiah saja (Bell et al., 2010). Pengetahuan ilmiah sudah seharusnya berkembang sebagai produk penyelidikan (Dewey, 1995). Begitu pula dalam pembelajaran, agar pengetahuan yang diperoleh mahasiswa lebih bermakna maka seharusnya diperoleh melalui proses penyelidikan. Pembelajaran inquiry akan lebih baik jika dilaksanakan dengan memasukkan elemen kolaborasi di dalamnya (Dillenbourg, 1999). Terdapat sejumlah argumen yang menyatakan bahwa dengan kolaborasi akan lebih efektif untuk pembelajaran

152 BRILIANT: Jurnal Riset dan Konseptual Volume 5 Nomor 1, Februari 2020 
inquiry. Teori pembelajaran sosio-konstruktivis memandang bahwa pengetahuan dibangun dari penyidikan secara kolaboratif dengan informasi yang didistribusikan diantara anggotanya. Dalam proses pembelajaran segala faktor seperti teman sekelas, guru, dan media teknis berperan penting dalam mencapai tujuan belajar (Crook, 1991). Sementara itu, berdasarkan pada refleksi teoritis dan studi empiris telah menunjukkan bahwa selain guru, potensi kolaborasi siswa dan peran media pembelajaran juga berperan untuk mencapai tujuan pembelajaran (Pilkington, 2004; Pilkington \& Walker, 2003). Pembelajaran CI diharapkan dapat menggiring mahasiswa untuk menemukan konsep fisika secara mendasar.

Pada pembelajaran mekanika Newtonan sudah seharusnya mahasiswa menemukan ide-ide pokok yang membangun konsep mekanika Newtonan secara mendasar. Untuk memahami konsep mekanika secara luas, maka mahasiswa harus memiliki pengetahuan yang kokoh terhadap topik kinematika seperti posisi, jarak dan perpindahan, kecepatan dan kelajuan, dan percepatan baik secara kualitatifkonseptual maupun secara kuantitatif-operasional (Sutopo, 2012). Untuk pembelajaran dinamika partikel, selain penguasaan kinematika yang baik, maka untuk memahami konsep gaya harus di bangun dari kemampuan siswa dalam membangun diagram gaya. Sejatinya gaya merupakan tarikan atau dorongan yang bekerja pada sebuah benda akibat berinteraksi dengan benda-benda lain baik secara langsung ataupun melalui medan. membangun konsep gaya apa saja yang timbul mahasiswa harus mampu mengidentifikasi interaksi tersebut hingga menuangkannya dalam diagram gaya. Dalam artikel ini akan diungkap bagaimana pemahaman konsep mahasiswa setelah pembelajaran CI berbasis diagram gerak dan diagram Interaksi.

Penggunaan diagram diagram interaksi dalam pembelajaran CI diharapkan mampu menjawab kesulitan-kesulitan yang dihadapi mahasiswa dalam belajar mekanika Newtonan. Tujuan penelitian ini untuk mengetahui bagaimana penguasaan konsep mekanika Newtonan calon sarjana Pendidikan Fisika Unesa yang belajar dengan CI berbantuan diagram gerak dan diagram interaksi. Selain itu untuk mengetahui kendala yang masih dihadapi setelah melaksanakan pembelajaran CI berbantuan diagram gerak dan interaksi.

\section{METODE}

Penelitian ini menggunakan pendekatan penelitian mixed methods dengan desain penelitian embedded Experimental Model yang diadaptasi dari (Creswell, 2014). Data yang diperoleh berupa data kuantitatif dan data kualitatif. Data kuantitatif yang diperoleh berupa data skor pretest-postest penguasaan konsep sedangkan data kualitatif diperoleh dari alasan yang diberikan oleh mahasiswa dalam menjawab soal pretes-postes.

Subjek penelitian ini adalah 38 mahasiswa yang sedang mengikuti perkuliahan Fisika Sekolah di Universitas Negeri Surabaya. Intrumen tes yang digunakan berupa 20 butir soal tes konseptual dalam format soal pilihan ganda beralasan. Indikator Penguasaan konsep yang diukur dapat dilihat pada Tabel 1.

Tabel 1. Indikator kemampuan penguasaan konsep

\begin{tabular}{|l|l|l|}
\hline Topik & Kemampuan yang diuji & No Soal \\
\hline Kinematika & $\begin{array}{l}\text { Menentukan posisi, perpindahan dan/atau jarak tempuh dari } \\
\text { persamaan } \vec{x}(t) \text { atau deskripsi verbal. }\end{array}$ & 1,2 \\
\cline { 2 - 3 } & Menentukan kecepatan dan/atau kelajuan dari diagram gerak, & $3,4,5$ \\
\hline
\end{tabular}




\begin{tabular}{|l|l|l|}
\hline \multirow{7}{*}{ Dinamika } & atau deskripsi verbal. & \\
\cline { 2 - 3 } & $\begin{array}{l}\text { Menentukan percepatan dari persamaan } \vec{x}(t) \text {, atau deskripsi } \\
\text { verbal }\end{array}$ & $6,7,8,9$ \\
\cline { 2 - 3 } & $\begin{array}{l}\text { Menentukan perbandingan } t_{\text {xmax }} \text { dua benda yang bergerak } \\
\text { parabola dimana ketinggian maksimum sama namin jangkauan } \\
\text { maksimum berbeda }\end{array}$ & 10 \\
\cline { 2 - 3 } & Membangun diagram gaya atau diagram bebas benda & 11,12 \\
\cline { 2 - 3 } & Merepresentasikan grafik $\vec{v}(t)$ ke dalam grafik $\vec{F}(t)$. & 13 \\
\cline { 2 - 3 } & $\begin{array}{l}\text { Menentukan besar dan/ atau arah resultan gaya dan/ atau } \\
\text { percepatan pada gerak melingkar beraturan, gerak lift ke } \\
\text { bawah sambil diperlambat, }\end{array}$ & $14,17,18,20$ \\
\cline { 2 - 3 } & $\begin{array}{l}\text { Menentukan hubungan } T_{\text {maks }} \text { dengan massa, kecepatan dan } \\
\text { panjang tali pada gerak melingkar. }\end{array}$ & 15 \\
\cline { 2 - 3 } & $\begin{array}{l}\text { Menentukan perbandingan gaya normal pada tiap titik pada } \\
\text { benda yang bergerak di atas bidang melingkar vertikal. }\end{array}$ & 16 \\
\cline { 2 - 3 } & Menentukan arah gaya normal & 19 \\
\hline
\end{tabular}

Seluruh soal tes yang digunakan dalam penelitian ini merupakan soal yang telah divalidasi oleh ahli. Selain itu, soal tersebut telah diujikan pada 84 responden yang merupakan mahasiswa pendidikan fisika di Universitas Negeri Surabaya. Soal tersebut merupakan soal terbaik dari total 24 soal pilihan ganda beralasan yang dirancang. Dengan $N=84$ diperoleh bahwa $r_{\text {tabel }}=0,1786$. Dari hasil perhitungan diperoleh 20 soal yang valid pada taraf signifikansi 0,05 karena berdasarkan analisis perhitungan diperoleh $r_{\text {pbis }}>r_{\text {tabel }}$ dan 4 soal tidak valid karena $r_{\text {pbis }}<r_{\text {tabel }}$ sehingga tidak digunakan dalam penelitian. Selanjutnya dilakukan perhitungan nilai Cronbach's Alpha untuk melihat tingkat keandalan instumen. Instrumen dikatakan andal jika nilai Cronbach's Alpha minimal sebesar 0,70 (DeVellis, 2016). Dari hasil perhitungan diperoleh nilai Cronbach's Alpha yakni sebesar 0,845 maka instrumen tes penguasaan konsep ini dapat dikatakan sebagai instrumen yang andal (Hair et al., 2010).

Pelaksanaan pembelajaran Collaborative Inquiry berbasis diagram gerak dan interaksi menggunakan 4 langkah pembelajaran yaitu: Problem framing, Collecting avidence, Analizing avidence, dan Celebreting and Sharing dilaksanakan dalam 4 kali pertemuan. Langkah-langkah pembelajaran diadaptasi dari Donohoo (2011) berbantuan diagram gerak pada materi kinematik partikel dan diagram interaksi pada materi dinamika partikel. Karena pembelajaran CI membutuhkan waktu yang cukup lama, maka kebutuhan data dan sumber lain pada langkah 1 dan 2 CI dapat disiapkan sebelum pelaksanaan pembelajaran. Secara garis besar langkah-langkah pembelajaran CI seperti pada Tabel 2.

Tabel 2. langkah-langkan pembelajaran CI

\begin{tabular}{|l|l|}
\hline Langkah CI & Keterangan \\
\hline $\begin{array}{l}\text { langkah 1. Problem } \\
\text { Framing }\end{array}$ & $\begin{array}{l}\text { Selama tahap ini, tim menentukan bersama visi, } \\
\text { mengembangkan penyelidikan tentang korelasi antara } \\
\text { praktek dan dasar teoritis, dan merumuskan teori tindakan. }\end{array}$ \\
\hline $\begin{array}{l}\text { langkah 2. Collecting } \\
\text { Evidence }\end{array}$ & $\begin{array}{l}\text { Pada tahap kedua, tim CI menentukan jenis data yang akan } \\
\text { dikumpulkan, cara mengumpulkan data, dan darimana data } \\
\text { itu dapat peroleh. }\end{array}$ \\
\hline $\begin{array}{l}\text { Langkah 3. Analizing } \\
\text { Evidence }\end{array}$ & $\begin{array}{l}\text { Tim belajar bagaimana membuat makna data dengan } \\
\text { mengidentifikasi pola dan tema. Data dianalisis dengan } \\
\text { menggunakan diagram gerak dan/atau diagram interaksi. } \\
\text { Selanjutnya merumuskan kesimpulan. Kegiatan akhir pada }\end{array}$ \\
\hline
\end{tabular}

154 BRILIANT: Jurnal Riset dan Konseptual Volume 5 Nomor 1, Februari 2020 


\begin{tabular}{|l|l|}
\hline & $\begin{array}{l}\text { tahap ini mendiskusikan hasil kerja bersama dalam kelompok } \\
\text { CI msing-masing. }\end{array}$ \\
\hline $\begin{array}{l}\text { langkah 4. Celebrating } \\
\text { and Sharing }\end{array}$ & $\begin{array}{l}\text { Salah satu kelompok CI maju untuk presentasi } \\
\text { menyampaikan hasil kerja CI. Kelompok lain mananggapi } \\
\text { untuk kemudian mendapatkan kesamaan konsep. }\end{array}$ \\
\hline
\end{tabular}

Data kuantitatif dianalisis untuk melihat perbedaan skor penguasaan konsep mahasiswa saat pretest dan posttest. Data pretest-postest diolah untuk kemudian disajikan dalam bentuk tabel data deskriptif yang menyajikan rata-rata skor, skor maksimum dan skor minimum, dan standar deviasi data. melihat signifikansi perbedaan skor pretest-postest digunakan uji t-berpasangan, dengan melihat kenormalan distribusi data yang dilihat dari nilai Skewness. Disamping itu, efektivitas pembelajaran diukur dengan $\mathrm{N}$-Gain (Hake, 1998) dari skor saat pretes ke skor saat postes. melihat kekuatan dampak pembelajaran terhadap penguasaan konsep digunakan perhitungan effect size $(d)$.

Data kualitatif dilakukan analisis mulai dari pengumpulan data, reduksi data, penyajian data, dan penarikan kesimpulan seperti langkah pada analisis Miles \& Huberman. Data kualitatif yang diperoleh dari alasan mahasiswa saat menjawab soal pretest-postest direduksi untuk memilih data yang sesuai dan penting untuk diangkat dalam penelitian. Pada tahap penyajian data, seluruh data yang direduksi dengan koding kemudian ditampilkan kembali secara naratif dengan bantuan uraian singkat, bagan, tabel atau grafik (Sugiyono, 2014)s. Pada tahap terakhir, kesimpulan diambil berdasarkan tahap penyajian data.

\section{HASIL}

\section{Penguasaan Konsep Mekanika Newtonan Pada Pembelajaran CI}

Pada hasil penelitian dipaparkan perubahan penguasaan konsep mekanika Newtonan. Sebelum itu, dilihat data perubahan skor seluruh mahasiswa dari pretest-postest. Hal tersebut didasarkan pada statistik deskriptif data pretestpostest mahasiswa. Informasi terkait skor minimal, maksimal rata-rata, standar deviasi, dan nilai skewness data pretest-postest dapat dilihat pada Tabel 3.

Tabel 3. Statistik Deskriptif skor Pretest-Posttest Penguasaan Konsep

\begin{tabular}{|l|l|l|}
\hline Statistik & Pretest & Posttest \\
\hline Minimum & 10 & 30 \\
\hline Maksimum & 65 & 95 \\
\hline Rata-rata & 31,71 & 58,16 \\
\hline Standar Deviasi & 11,46 & 13,17 \\
\hline Skewness & $\mathbf{0 , 5 9 1}$ & $\mathbf{0 , 3 3 0}$ \\
\hline
\end{tabular}

Tabel 3 menunjukkan bahwa penguasaan konsep mekanika newtonan mengalami peningkatan dilihat nilai postes yang lebih tinggi dibanding nilai pretes dengan rata-rata berturut-turut 58,16 dan 31,71. Nilai Skewnes berturutturut 0,591 dan 0,330. Nilai tersebut berada dalam interval antara -1 dan 1 yang menunjukkan bahwa data tersebut terdistribusi normal (Morganet et al., 2011; Leech et al., 2005), sehingga dapat diketahui signifikansi perbedaan skor pretest dan postest menggunakan uji t-berpasangan. Dari hasil uji- $t$ berpasangan diperoleh $(t=-11,16)$ dengan signifikansi $(p=0,00)$. Nilai $p<0,05$ menunjukkan bahwa data skor pretest-postest mekanika newtonan berbeda secara signifikan. Sementara itu nilai gain ternormalisasi kelas Ngain sebesar 0,38 dan dapat 
disimpulkan bahwa skor mahasiswa mengalami peningkatan pada kategori sedang (Hake, 1998). Kemudian dari nilai effect size diperoleh $\mathrm{d}=2,17$ yang menunjukkan bahwa perbedaan antara skor pretes dan postes dalam kategori kuat (Cohen et al., 2007).

Dalam artikel ini hanya dipilih satu soal yakni butir soal nomor 11 untuk dibahas. Soal nomor 11 merupakan soal dengan peningkatan jumlah mahasiswa memilih opsi benar yang paling tinggi, yang mengindikasikan keberhasilan pembelajaran dalam menguatkan konsep. Soal nomor 11 menguji kemampuan mahasiswa dalam membangun Free Boby-Diagrams' (FBDs). Butir soal nomor 11 dapat dilihat pada Gambar 1.

\footnotetext{
Balok A (bermassa $2 m$ ) dan B (bermassa $m$ ) diletakkan di atas meja yang permukaannya kasar seperi gambar. Balok A didorong ke kanan dengan gaya konstan $\vec{F}$ sehingga kedua

balok bergerak lurus berubah beraturan ke kanan. Selama gerakan tersebut, kedua balok selalu bersentuhan. Diantara diagram-diagram gaya berikut, manakah yang

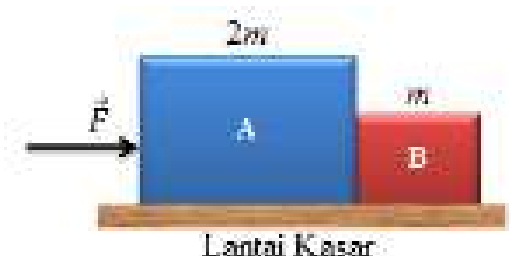

Lantai Kasar

paling tepat menggambarkan gaya-gaya yang bekerja pada balok B? (Catatan: $\vec{F}_{A \rightarrow E} \equiv$ gaya dorong balok A ke B; $\vec{F}_{\mathrm{B} \rightarrow \mathrm{A}} \equiv$ gaya dorong balok B ke A; $\vec{w}_{A} \equiv$ gaya berat balok A oleh bumi; $\vec{f}_{h A} \equiv$ gaya gesek kinetis oleh permukaan meja pada balok A; $\vec{f}_{h o}$ Egaya gesek kinetis oleh permukaan meja pada balok B; $\vec{N} \equiv$ gaya normal pada balok A oleh meja).
}

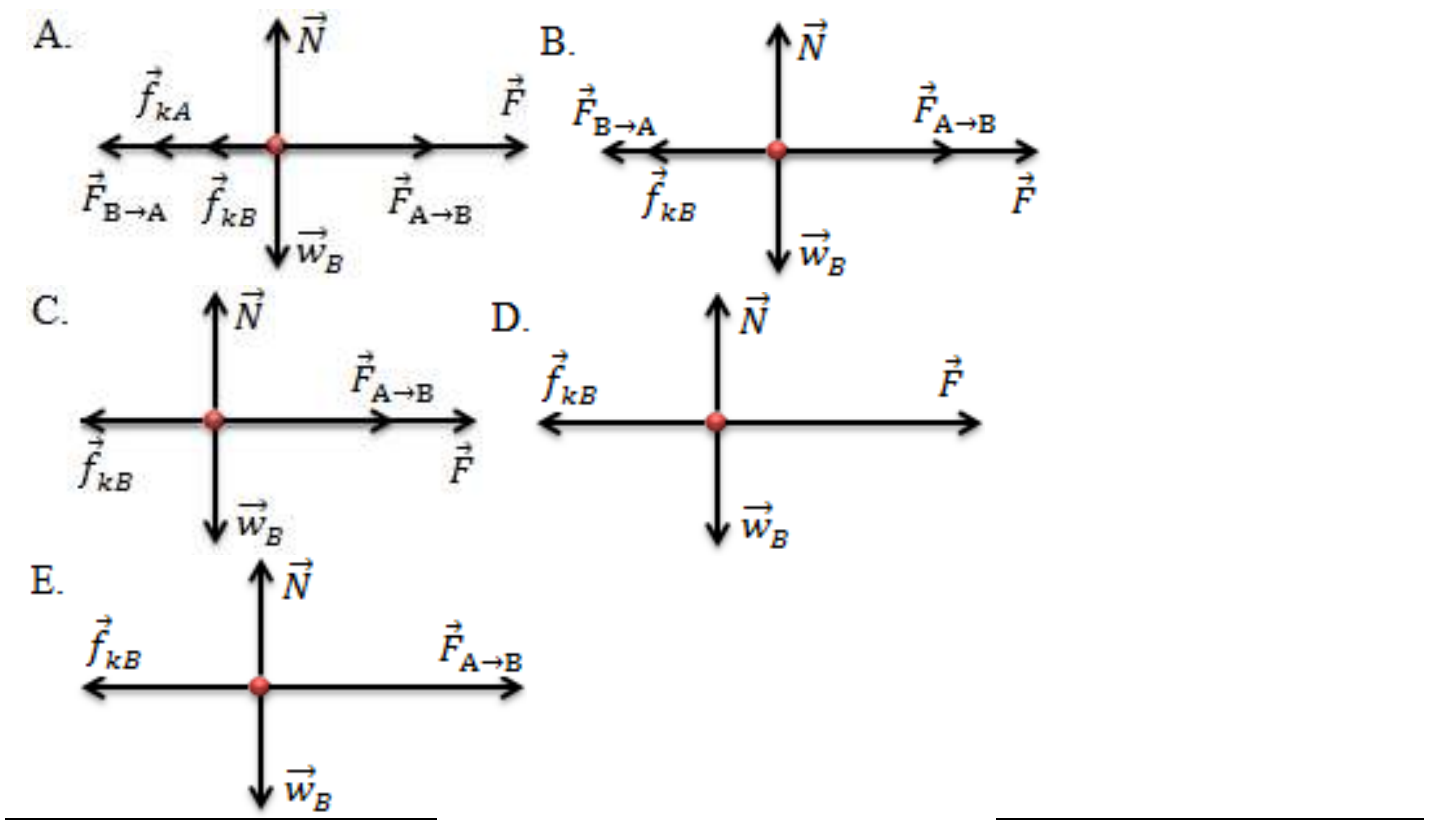

Gambar 1. Soal Pretes-Postes nomor 5

Perubahan jumlah mahasiswa dalam menjawab soal nomor 11 dapat dilihat pada Tabel 4. Cara menjawab atau alasan jawaban mahasiswa dalam menjawab postes dapat dilihat pada Tabel 5.

Tabel 4. Crosstabulation Nilai Pretes-Postes Soal Nomor 11 


\begin{tabular}{|c|c|c|c|c|c|c|c|c|}
\hline & \multicolumn{6}{|c|}{ POSTES } & \multicolumn{2}{|c|}{ JUMLAH } \\
\hline & & $\mathrm{A}$ & $\mathrm{B}$ & $\mathrm{C}$ & $\mathrm{D}$ & $E$ & Angka & $\%$ \\
\hline \multirow{5}{*}{ 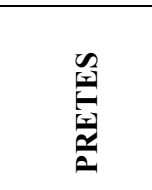 } & $\mathrm{A}$ & 0 & 0 & 0 & 2 & 5 & 7 & 18.42 \\
\hline & $\mathrm{B}$ & 0 & 0 & 1 & 0 & 10 & 11 & 28.95 \\
\hline & $\mathrm{C}$ & 0 & 0 & 0 & 1 & 3 & 4 & 10.53 \\
\hline & $\mathrm{D}$ & 1 & 1 & 1 & 0 & 11 & 14 & 36.84 \\
\hline & $\mathrm{E}^{*}$ & 0 & 0 & 0 & 0 & 2 & 2 & 5.26 \\
\hline \multirow{2}{*}{ JUMLAH } & Angka & 1 & 1 & 2 & 3 & 31 & \multirow{2}{*}{38} & \multirow{2}{*}{100} \\
\hline & $\%$ & 2.63 & 2.63 & 5.26 & 7.89 & 81.58 & & \\
\hline
\end{tabular}

Tabel 5. Jawaban Postes Mahasiswa soal nomor 11

\begin{tabular}{|c|c|c|}
\hline $\begin{array}{c}\text { Pilihan } \\
\text { Jawaban }\end{array}$ & Cara Penyelesaian Soal/Alasan Jawaban & $\begin{array}{c}\text { Jumlah } \\
\text { Mahasiswa }\end{array}$ \\
\hline A & $\begin{array}{l}\text { Menggunakan diagram interaksi. Karena benda B menempel dengan } \\
\text { benda A dan lantai kasar maka semua gaya yang muncul bekerja pada } \\
\text { benda B. }\end{array}$ & 1 \\
\hline $\mathrm{B}$ & $\begin{array}{l}\text { Menggunakan diagram interaksi sebelum menggambar diagram gaya. } \\
\text { Karena benda B menempel dengan A dan lantai, maka selain gaya gesek } \\
\text { yang dialami benda A semua gaya bekerja pada benda B. }\end{array}$ & 1 \\
\hline $\mathrm{C}$ & $\begin{array}{l}\text { Menggunakan diagram interaksi sebelum menggambar diagram gaya. } \\
\text { Karena benda B menempel pada benda A maka selain gaya oleh B ke A } \\
\vec{F}_{D \rightarrow A} \text { dan gaya gesek yang dialami A } \vec{F}_{\hat{k} A} \text { semua gaya bekerja ke B } \\
\text { termasuk } \vec{F} \text {. }\end{array}$ & 2 \\
\hline $\mathrm{D}$ & $\begin{array}{l}\text { Menggunakan diagram interaksi sebelum menggambar diagram gaya. } \\
\text { Karena lantai kassar bekerja } \vec{f}_{k \vec{b}} \text {. Benda B menempel dengan benda } \mathrm{A} \\
\text { sehingga gaya } \vec{F} \text { juga dialami } \mathrm{B}\end{array}$ & 3 \\
\hline $\mathrm{E}^{*}$ & $\begin{array}{l}\text { Menggunakan diagram interaksi sebelum menggambar diagram gaya . } \\
\text { Hanya fokus pada benda B. Karena kontak dengan benda A maka ada } \\
\text { doromgan oleh A sebesar } \vec{F}_{\vec{B}-\rightarrow A} \text {. Lantai kasar menyebabkan gesekan } \vec{f}_{\text {has }}\end{array}$ & 31 \\
\hline
\end{tabular}

Keterangan *= Jawaban benar

Tabel 4 menunjukkan sebanyak 7 mahasiswa $(18,42 \%)$ saat pretes memilih jawaban A. Semula mereka berpendapat bahwa gaya-gaya yang bekerja pada benda B ditentukan dengan cara menggunakan HK III Newton. Lanjut mereka, karena benda B menempel dengan benda A dan lantai kasar maka gaya yang muncul semua bekerja pada benda B. Mereka mengenal Hukum III newton, bahwa apabila sebuah benda memberikan aksi pada benda lain, maka aka muncul reaksi dari benda lain dengan besar sama dan arah berbeda. Karena benda A mendorong benda $\mathrm{B}$ maka benda $\mathrm{A}$ memberikan aksi pada benda $\mathrm{B}$ sehingga muncul $\vec{F}_{A \rightarrow B}$ dan $\vec{F}_{B \rightarrow A}$, sehingga menurut mereka semua gaya yang ada bekerja pada benda B. Setelah belajar dengan CI berbentuan diagram interaksi, sebanyak 5 mahasiswa merubah jawaban mereka dengan cara menggunakan diagram interaksi sebelum menggambar diagram gaya .Karena benda $\mathrm{B}$ kontak dengan benda A maka ada doromgan oleh A sebesar $\vec{F}_{\bar{E} \rightarrow A}$. Lantai kasar menyebabkan gesekan $\vec{f}_{k \vec{s}}$. Mereka sudah memahami bahwa gaya-gaya yang bekerja pada benda $\mathrm{B}$ hanyalah gaya yang dihasilkan dari interaksi benda B dengan lingkungannya, sehingga gaya yang bekerja padanya hanya $\vec{F}_{\vec{B} \rightarrow A}, \vec{k}_{\vec{\theta}}$, gaya $\operatorname{Normal}(\vec{N})$ dan gaya berat $(\vec{w})$ sesuai pilihan jawaban E.

Sebanyak 10 mahasiswa (26,32\%) yang semula memilih jawaban B berubah memilih jawaban E setelah pembelajaran CI. Semula mereka berpendapat bahwa gaya-gaya yang bekerja pada benda $\mathrm{B}$ ditentukan dengan cara menggunakan HK III Newton. Karena benda B menempel pada benda A, maka 
gaya yang bekerja pada A yaitu F juga dianggap bekerja langsung pada benda B. Mereka sudah baik dalam penguasaan gaya gesek, bahwa gaya gesek yang bekerja pada satu bendatidak dapat bekerja pada benda lain. Mereka menyimpulkan, selain gaya gesek $\vec{f}_{\text {hA }}$ semua gaya bekerja pada benda B dan sesuai dengan pilihan jawaban B. Namun setelah mengikuti pembelajaran CI berbantuan diagram interaksi, penguasaaan konsep mereka tentang gaya berubah lebih baik. Mereka menggunakan diagram interaksi sebelum menggambar diagram gaya dan hanya fokus pada benda B. Karena kontak dengan benda A maka ada dorongan oleh benda A terhadap benda B sebesar $\vec{F}_{A \rightarrow E}$. Karena Lantai kasar menyebabkan gesekan $\vec{f}_{\vec{e}}$ yang bekerja pada benda B, sehingga gambar FBDs pada benda B seperti yang ditunjukkan pilihan jawaban E.

Kelompok mahasiswa yang semula memilih jawaban C, 11 mahasiswa berubah memilih jawaban E. Kelompok ini sebelumnya juga menggunakan HK III Newton dalam menggambar FBDs. Kelompok ini sudah lebih fokus hanya pada benda $\mathrm{B}$, berbeda dengan yang seelumnya memilij jawaban $\mathrm{B}$, mereka menghilangkan faktor $\vec{F}_{\vec{E} \rightarrow A}$ dan dianggap bekerja pada benda A saja. Namun kelompok ini tidak dapat menghilangkan gaya $\mathrm{F}$, dengan anggapan gaya ini juga bekerja pada benda B. Namun setelah belajar dengan CI berbantuan diagram interaksi, penguasaan konsep mereka menjadi lebih baik. Mereka menggunakan diagram interaksi sebelum menggambar diagram gaya dan hanya fokus pada benda B. Karena kontak dengan benda A maka ada dorongan oleh benda A terhadap benda B sebesar $\vec{F}_{A \rightarrow \vec{E}}$. Karena Lantai kasar menyebabkan gesekan $\vec{f}_{k s}$ yang bekerja pada benda B, sehingga gambar FBDs pada benda B seperti yang ditunjukkan pilihan jawaban $\mathrm{E}$.

\section{PEMBAHASAN}

Pembelajaran CI berhasil merubah penguasaan konsep mahasiswa pada materi dinamika partikel. Semula mahasiswa mengenal Hukum-hukum Newton dan macam-macam gaya seperti gaya berat $(\boldsymbol{w})$, gaya normal $(\boldsymbol{N})$, gaya tarik/dorong $(\boldsymbol{F})$ gaya gesek $(\boldsymbol{f})$ dan lainnya. Gaya-gaya ini digunakan oleh mahasiswa setiap mengerjakan soal yang menerapkan konsep gaya. Dalam benak mereka kalau ada gaya berat dan ada kontak dengan lantai secara otomatis ada gaya normal. Jika lantainya kasar muncul gaya gesek Jika dua atau beberapa benda menempel dan salah satu diberi gaya F, maka benda yang lain juga mendapat gaya F. Sementara Hukum III Newton dimaknai sebagai pasangan aksi reaksi secara konseptual, jika ada benda yang memberikan aksi secara otomatis akan muncul reaksi dari benda itu dengan arah yang sama dan arah berlawanan.

Pemahaman gaya yang sepotong-sepotong dan cenderung hafalan menyebabkan mahasiswa kesulitan ketika diminta menggambarkan FBDs, terlihat saat pretes hanya 2 mahasiswa yang menjawab benar pada soal nomor 11, itupun dengan alasan yang masih kurang konsisten dan cenderung menebak. Setelah pembelajaran CI konsep mereka tentang gaya berubah secara signifikan. Hal ini cukup beralasan karena mereka sudah mengenal bahkan mampu menggunkan diagram interaksi dalama menyelesaikan persoalan yang melibatkan konsep gaya. Sangat penting memahami konsep gaya dari hasil interaksi (Brown, 1989; Hellingman, 1989; Jiménez \& Perales, 2001; Reif et al., 1992; Van Heuvelen \& Zou, 2001) agar mahasiswa tidak keliru dalam mengonstruksi diagram gaya pada benda. Penggunaan diagram interaksi didasarkan pada pemahaman bahwa "tidak 
mungkin sebuah benda bergerak dengan sendirinya tanpa digerakkan oleh benda lain". Pemahaman itu berindikasi terhadap harus adanya interaksi antar dua benda. Interaksi tersebut dapat secara kontak langsung atau karena pengaruh medan seperti interaksi grafitasi dan interaksi Coulomb, keduanya dikenal dengan interaksi medan. Sementara gaya dipahami sebagai hasil interaksi tersebut. Ketika mahasiswa sudah memahami interaksi dan mampu menggambarkan interaksi antar benda, maka gaya apa saja sebagai hasil interaksi dapat ditentukan. Jika mahasiswa mampu mengidentifikasi interaksi antar objek secara benar pada kasus yang disajikan dengan menggunakan DI, maka DI juga menjadi sarana untuk mengidentifikasi gaya yang bekerja pada objek dan ini merupakan cara untuk membantu siswa dalam membangun FBDs (Savinainen, Mäkynen, Nieminen, \& Viiri, 2013). Keberhasilan CI berbasis diagram interaksi pada konsep gaya khususnya dalam menggambar FBDs dapat ditunjukkan dengan sejumlah 29 mahasiswa $(76,32 \%)$ menjawab benar soal nomor 11 pada saat postes.

Walaupun secara umum penguasaan konsep mekanika Newtonan mahasiswa meningkat bukan berarti tidak ada kendala selama pelaksanaan pembelajaran CI. Pertama, waktu yang pendek menyebabkan kegiatan inquiry yang dilakukan belum maksimal, dibutuhkan strategi pengelolaan waktu yang efektif, misalnya dengan menyiapkan contoh macam-macam gerak lengkap dengan diagram geraknya dengan memanfaatkan media pembelajaran baik cetak maupun elektronik. Kedua, dalam menyelesaikan soal, mahasiswa masih bingung dalam menggambarkan gaya jika soal terdiri dari beberapa objek. Objek masih bingung dalam memaknai interaksi antara sistem dan lingkungan dan antar objek dalam sistem.

\section{KESIMPULAN}

Berdasarkan hasil dan pembahasan dapat disimpulkan bahwa pembelajaran Collaborative Inquiry (CI) berbantuan diagram interksi berhasil dan efektif meningkatkan penguasaan konsep mekanika Newtonan Mahasiswa pada perkuliahan Fisika Sekolah di Universitas Negeri Surabaya. Peningkatan ini ditunjukkan dari nilai postes yang lebih tinggi dibanding nilai pretes dengan ratarata berturut-turut 58,16 dan 31,71. Hasil tersebut berbeda secara signifikan dengan $(t=-11,16$ dan $p=0,00)$, nilai gain ternormalisasi kelas berkategori sedang $($ Ngain $=0,38)$, dan nilai effect size berkategori kuat $(d=2,17)$.

\section{SARAN}

Dengan pelaksanaan kegiatan inquiry yang cukup memakan waktu, diharapkan pembelajaran direncanakan dengan sebaik mungkin. Selain itu, berdasarkan temuan dalam penelitian ini, mahasiswa sulit dalam mengidentifikasi interaksi antara objek dalam sistem dengan lingkungan dan interaksi antar objek dalam sistem. Oleh karena itu, dalam penelitian kedepan permasalahan tersebut memberikan peluang untuk memperoleh perhatian khusus dalam penelitian pembelajaran.

\section{DAFTAR RUJUKAN}

Angin, S. L., Parno, \& Sutopo. (2017). Pemahaman Mahasiswa Tentang Multirepresentasi Konsep Percepatan. Jurnal Riset \& Kajian Pendidikan Fisika, 4(2), 48-53. 
Arends, R. I. (2008). Learning to Teach (7th ed.). Boston: McGraw-Hill Higher Education.

Atasoy, S., Kucuk, M., \& Akdeniz, A. R. (2011). Remedying science student teachers' misconceptions of force and motion using worksheets based on constructivist learning theory. Energy Education Science and Technology Part B: Social and Educational Studies, 3(4), 653-668.

Aufschnaiter, C., \& Rogge, C. (2010). Misconceptions or missing conceptions? Eurasia Journal of Mathematics, Science and Technology Education, 6(1), 3-18. https://doi.org/10.12973/ejmste/75223

Başer, M. (2006). Effect of conceptual change oriented instruction on remediation of students misconceptions related to heat and temperature concepts. Journal of Maltese Education Research, 4(1), 64-79. https://doi.org/10.1061/(ASCE)0733-9410(1991)117

Bell, T., Urhahne, D., Schanze, S., \& Ploetzner, R. (2010). Collaborative inquiry learning: Models, tools, and challenges. International Journal of Science Education, 32(3), 349-377. https://doi.org/10.1080/09500690802582241

Berek, F. X., Sutopo, S., \& Munzil, M. (2016). Concept enhancement of junior high school students in hydrostatic pressure and archimedes law by predictobserve-explain strategy. Jurnal Pendidikan IPA Indonesia, 5(2), 230-238. https://doi.org/10.15294/jpii.v5i2.6038

Brown, D. E. (1989). Students' concepts of force: The importance of understanding Newton's Third Law. Physics Education, 24(6), 353-358.

Clement, J. (1982). Students' preconceptions in introductory mechanics. American Journal of Physics, 50(1), 66-71. https://doi.org/10.1119/1.12989

Cohen, L., Manion, L. M., \& Morrison, K. (2007). Research Methods in Education (Sixth). London: Routledge Taylor \& Francis Group. https://doi.org/10.1111/j.1467-8527.2007.00388_4.x

Creswell, J. W. (2014). Research Design: Qualitative, Quantitative, and Mixed Methods Approaches (4th ed.). London: Sage Publication Ltd.

Crook, C. (1991). Computers in the zone of proximal development: Implications for evaluation. Computers and Education, 17(1), 81-91. https://doi.org/10.1016/0360-1315(91)90075-3

DeVellis, R. (2016). Scale development: Theory and applications. California: Sage.

Dewey, J. (1995). Science as subject-matter and as method. Science \& Education, 4(4), 391-398. https://doi.org/10.1007/BF00487760

Dillenbourg, P. (1999). Introduction: What do you mean by "collaborative learning"? In Collaborative learning: Cognitive and computational approaches (pp. 1-19). Retrieved from https://telearn.archivesouvertes.fr/hal-00190240

Docktor, J. L., \& Mestre, J. P. (2014). Synthesis of discipline-based education research in physics. Physical Review Special Topics - Physics Education Research, 10(2), 1-148. https://doi.org/10.1103/PhysRevSTPER.10.020119

Donohoo, J. (2011). Collaborative inquiry: A facilitator's guide. MISA. Ontario: Learning Forward Ontario.

Flores, S., Kanim, S. E., \& Kautz, C. H. (2004). Student use of vectors in introductory mechanics. American Journal of Physics, 72(4), 460-468. https://doi.org/10.1119/1.1648686 
Gilbert, J. K., \& Watts, D. M. (1983). Concepts, Misconceptions and Alternative Conceptions: Changing Perspectives in Science Education. Journal of Market-Focused Management, 10(1), 61-98. https://doi.org/10.1080/03057268308559905

Hair, J. F., Black, W. C., Babin, B. J., \& Anderson, R. E. (2010). Multivariate Data Analysis (7th ed.). New Jersey: Prentice Hall, Upper Saddle River.

Hake, R. R. (1998). Interactive-engagement versus traditional methods: A sixthousand-student survey of mechanics test data for introductory physics courses. American Journal of Physics, 66(1), 64-74. https://doi.org/10.1119/1.18809

Halloun, I. A., \& Hestenes, D. (1985). Common sense concepts about motion. American Journal of Physics, 53(11), 1056-1065. https://doi.org/10.1119/1.14031

Hellingman, C. (1989). Do forces have twin brothers? Physics Education, 24(1), 36-40. https://doi.org/10.1088/0031-9120/24/1/311

Hestenes, D., \& Wells, M. (1992). A mechanics baseline test. The Physics Teacher, 30(3), 159-166. https://doi.org/10.1119/1.2343498

Jiménez, J. de D., \& Perales, F. J. (2001). Graphic representation of force in secondary education: analysis and alternative educational proposals. Physics Education, 36, 227-235. https://doi.org/10.1088/0031-9120/36/3/309

Knight, R. D. (1995). The vector knowledge of beginning physics students. The Physics Teacher. https://doi.org/10.1119/1.2344143

Leech, N. L., Barrett, K. C., \& Morgan, G. A. (2005). SPSS For Intermediate Statistics: Use and Interpretation (Second). London: Lawrence Erlbaum Associates.

Morgan, G. A., Barrett, K. C., Leech, N. L., \& Gloeckner, G. W. (2011). IBM SPSS for Introductory Statistics: Use and Interpretation. IBM SPSS for Introductory Statistics: Use and Interpretation. New York: Taylor and Francis Group. https://doi.org/10.4324/9780429287657

Nguyen, N.-L., \& Meltzer, D. E. (2003). Initial understanding of vector concepts among students in introductory physics courses. American Journal of Physics, 71(6), 630-638. https://doi.org/10.1119/1.1571831

Pilkington, R. M. (2004). Developing discussion for learning. Journal of Computer Assisted Learning, 20(3), 161-164. https://doi.org/10.1111/j.13652729.2004.00080.x

Pilkington, R. M., \& Walker, S. A. (2003). Facilitating debate in networked learning: Reflecting on online synchronous discussion in higher education. In Instructional Science (Vol. 31, pp. 41-63). https://doi.org/10.1023/A:1022556401959

Reif, F., Allen, S., Cognition, S., \& Reif, F. (1992). Cognition for Interpreting Scientific Concepts : A Study of Acceleration Linked references are available on JSTOR for this article : Cognition for Interpreting Scientific Concepts : A Study of Acceleration, 9(1), 1-44. https://doi.org/10.1207/s1532690xci0901

Saputri, D. E., Taqwa, M. R. A., Aini, F. N., Shodiqin, I., \& Rivaldo, L. (2019). Pemahaman konsep mekanika: menentukan arah percepatan pendulum, sulitkah? Jurnal Pendidikan Fisika Dan Teknologi, 5(1), 110-117. https://doi.org/10.29303/jpft.v5i1.1134

Savinainen, A., Mäkynen, A., Nieminen, P., \& Viiri, J. (2013). Does using a 
visual-representation tool foster students' ability to identify forces and construct free-body diagrams? Physical Review Special Topics - Physics Education Research, 9(1), 1-11. https://doi.org/10.1103/PhysRevSTPER.9.010104

Shaffer, P. S., \& McDermott, L. C. (2005). A research-based approach to improving student understanding of the vector nature of kinematical concepts. American Journal of Physics, 73(10), 921-931. https://doi.org/10.1119/1.2000976

Sugiyono. (2014). Metode Penelitian Kuantitatif, Kualitatif, dan R\&D. Bandung: Alfabeta.

Sutopo. (2016). Pemahaman Mahasiswa Tentang Konsep-Konsep Dasar Gelombang Mekanik. Jurnal Pendidikan Fisika Indonesia, 12(1), 41-53. https://doi.org/10.15294/jpfi

Sutopo, S. (2012). Pembelajaran Kinematika Berbasis Diagram Gerak: Cara Baru Dalam Pengajaran Kinematika. In Seminar Nasional Penelitian Universitas Negeri Yogyakarta (p. 11). Yogyakarta: Universitas Negeri Yogyakarta. https://doi.org/10.13140/RG.2.1.1964.6560

Taqwa, M. R. A. (2017). Profil Pemahaman Konsep Mahasiswa dalam Menentukan Arah Resultan Gaya. In Prosiding Seminar Nasional Pendidikan Sains (pp. 79-87).

Taqwa, M. R. A., Hidayat, A., \& Supoto. (2017). Konsistensi Pemahaman Konsep Kecepatan dalam Berbagai Representasi. Jurnal Riset \& Kajian Pendidikan Fisika, 4(1), 31-39.https://doi.org/http://dx.doi.org/10.12928/jrkpf.v4i1.6469

Taqwa, M. R. A., \& Pilendia, D. (2018). Kekeliruan Memahami Konsep Gaya , Apakah Pasti Miskonsepsi? Jurnal Inovasi Pendidikan Fisika Dan Integrasinya, 01(02), 1-12.

Taqwa, M. R. A., Priyadi, R., \& Rivaldo, L. (2019). Pemahaman Konsep Suhu dan Kalor Mahasiswa Calon Guru. Jurnal Pendidikan Fisika, 7(1), 56-67.

Taqwa, M. R. A., \& Rivaldo, L. (2018). Kinematics Conceptual Understanding: Interpretation of Position Equations as A Function of Time. Jurnal Pendidikan Sains, 6(4), 120-127. https://doi.org/http://dx.doi.org/10.17977/jps.v6i4.11274

Taqwa, M. R. A., \& Rivaldo, L. (2019). Pembelajaran Problem Solving Terintegrasi PhET: Membangun Pemahaman Konsep Listrik Dinamis. Kwangsan: Jurnal Teknologi Pendidikan, 07(01), 45-56. https://doi.org/http://dx.doi.org/10.31800/jtp.kw.v7n1.p45--56

Van Heuvelen, A., \& Zou, X. (2001). Multiple representations of work-energy processes. American Journal of Physics, 69(2), 184-194. https://doi.org/10.1119/1.1286662 